\title{
KONSEP DAN MANFAAT PENGATURAN SAHAM TANPA NILAI NOMINAL DALAM PASAR MODAL INDONESIA*
}

\author{
Ida Keriahenta Silalahi dan Nur Sayidah \\ Fakultas Hukum dan Fakultas Ekonomi Univ. Dr. Soetomo Surabaya \\ E-mail: idasilalahi2012@yahoo.co.id; nsayidah@yahoo.co.id
}

\begin{abstract}
The purpose of this research is to find out the concept and benefit of regulation of no par value shares in Indonesian Capital Market. The legal issue of this research is the philosophical meaning of no par value shares as stipulated in Article 31 subsection (2) of Company Law 2007. Ontologically, regulation of no par value shares is one of alternatives to solve the crisis of capital market. Etiologically, the regulation will give the value of benefits in term of providing easiness to perform corporate action, simplification of accounting, no distinction between issued shares and outstanding shares, the shares price is not determined by the nominal price but the market price, it remains to be traded, the company may still do a rights issue to obtain fresh funds even during crisis and they can use mandatory and optional system.
\end{abstract}

Keywords: regulation, no par value shares, capital market.

\begin{abstract}
Abstrak
Penelitian ini bertujuan untuk menemukan konsep hukum dan manfaat pengaturan saham tanpa nilai nominal di pasar modal Indonesia. Isu hukum dalam penelitian ini adalah makna filosofi saham tanpa nilai nominal sebagaimana tercantum dalam Pasal 31 ayat (2) UUPT 2007. Berdasarkan ontologinya pengaturan saham tanpa nilai nominal bermanfaat sebagai salah satu alternatif mengatasi krisis pasar modal. Sementara berdasarkan aksiologinya pengaturan ini memberikan nilai menfaat yaitu kemudahan untuk melakukan corporate action, penyederhanaan pembukuan, tidak ada pembedaan antara saham ditempatkan dan saham disetor, harga saham tidak ditentukan oleh harga nominal tetapi harga pasar, masih tetap dapat diperdagangkan, perusahaan masih tetap dapat melakukan right issue untuk memperoleh dana segar dan dapat menggunakan sistem mandatory dan optional.
\end{abstract}

Kata Kunci: pengaturan, saham tanpa nilai nominal, pasar modal

Pendahuluan

Pengaturan atau penerapan saham tanpa nilai nominal dalam perdagangan saham di pasar modal Indonesia saat ini merupakan sebuah kebutuhan. Ada beberapa alasan yang melatar belakanginya, salah satunya dikarenakan adanya krisis (bearish) yang berulangkali melanda pasar modal Indonesia. Pasar modal bearish terjadi ketika ada penurunan yang tajam dalam harga saham atau instrument investasi lainnya, sehingga return saham riil mendekati nol. ${ }^{1}$

Artikel ini merupakan artikel hasil penelitian dengan Skim Penelitian Hibah Bersaing, dilaksanakan dengan Surat Perjanjian Penelitian No. 094/SP2H/PDSTRL/K7/KL/ III/2013.

1 Shen Pu, "The P/E Ratio and Stock Market Performance", Economic Review, Vol. 85, No. 4 Fourth Quarter
Beberapa negara seperti Jepang, Singapura, Australia dan Amerika Serikat merupakan contoh negara-negara yang menyelesaikan krisis pasar modal dengan membuat perubahan hukum dalam rangka penerapan saham tanpa nilai nominal. Perubahan hukum di Jepang dilakukan dengan membuat amandemen terhadap peraturan sistem keuangannya pada tanggal 1 Oktober 2001. ${ }^{2}$ Financial System Reform Law telah

2000, Kansas: Federal Reserve Bank of Kansas City, hlm.23-36; Ernie Hendrawaty, "Evaluasi Kinerja Reksa Dana Campuran Indonesia pada Kondisi Pasar Bearish", Jurnal Bisnis dan Manajemen, Vol. 6 No.3, Mei 2010, Lampung: Fakultas Ekonomi Universitas Lampung, hlm. 385.

2 Japan Securities Research Institute, Securities Market In Japan, 2006, Tokyo: Japan Securities Research Institute, hlm. 60. 
mengganti the Tan'l kabu system (sistem saham dengan nilai nominal) menjadi the Tangen-kabu system (sistem saham tanpa nilai nominal). Singapura melakukan perubahan terhadap Common Law mereka pada tahun $2006^{3}$. Saham tanpa nilai nominal juga populer di Kanada. ${ }^{4}$

Alasan-alasan ini melatar belakangi perlunya pengaturan saham tanpa nilai nominal di Indonesia. Perturan saham tanpa nilai nominal tercantum dalam Pasal 31 ayat (2) Undang-undang No. 40 tentang Perseroan (selanjutnya disingkat UUPT). Ketentuan umum UUPT 2007 menyatakan bahwa seluruh modal dari Perseroan terdiri dari saham. Saham yang diisyaratkan adalah saham dengan nilai nominal yang ditegaskan dalam Pasal 49 ayat 2. Pengeluaran saham tanpa nilai nominal (no par value) hanya berlaku bagi Perseroan yang telah menawarkan saham di pasar modal (Perseroan Terbuka). Artinya perusahaan yang sudah terdaftar di bursa efek mempunyai kesempatan untuk menerbitkan saham tanpa nilai nominal. Kesempatan ini sampai saat ini belum bisa digunakan karena belum ada pengaturan lebih lanjut. Konsep saham tanpa nilai nominal belum ada di Undang-undang Pasar Modal, sehingga ada permasalahan hukum dalam penerapannya. Permasalahan yuridis ini menyebabkan terjadinya kekosongan hukum, sehingga perlu segera diisi dengan sebuah pengaturan.

Penelitian yang khusus membahasa pengaturan saham tanpa nilai nominal di Indonesia, sepanjang pengamatan penulis melalui kepustakaan dan e-library belum pernah ada. Beberapa penelitian yang ada hanya tentang pengaturan pasar modal seperti yang dilakukan oleh SimboIon $(2003)^{5}$ dan Wijaya (2009) ${ }^{6}$. Hasil penelitian Simbolon 2003) menunjukkan manfaat atau tu-

3 Gunawan Widjaya, “Aspek Hukum Saham Tanpa Nilai Nominal dan Implikasinya Bagi PT Terbatas dan Pasar modal Indonesia", Jurnal Hukum Bisnis, Vol. 28 No. 3 2009, Jakarta: Yayasan Pengembang Hukum Bisnis, hlm. 24.

4 Anonymous, "Corporations : No Par Value Stock", Michigan Law Review, Vol. 22 No. 8 Edisi Juni 1924, Michigan: The University of Michigan Law School, hlm.840.

5 Robinson Simbolon, "Pentingnya Perubahan Undang undang Nomor 8 Tahun 1995 tentang Pasar Modal”, Jurnal Hukum Bisnis, Vol. 14. Edisi Juli 2003, Jakarta: Yayasan Pengembang Hukum Bisnis, hlm. 5-6.

6 Gunawan Widjaya, op.cit. hlm. 28. juan yang menjadi alasan pengaturan pasar modal adalah melindungi kepentingan investor, menjamin terselenggaranya kegiatan pasar modal yang teratur, wajar dan efesien serta menekan resiko sistemik yang disebabkan dari kegagalan sektor jasa keuangan atau sebaliknya. Hasil penelitian Wijaya (2009) menunjukan bahwa setiap jenis saham baik dengan nilai nominal atau tanpa nilai nominal mempunyai kerugian dan keuntungan masing-masing. Masih minimnya penelitian tentang saham tanpa nilai nominal ini memotivasi peneliti untuk melakukan penelitian lebih lanjut terkait konsep hukum dan manfaat pengaturan saham tanpa nilai nominal.

\section{Permasalahan}

Permasalahan yang dibahas pada artikel penelitian ini adalah mengenai konsep hukum pengaturan saham tanpa nilai nominal dan apa manfaatnya.

\section{Metode Penelitian}

Penelitian ini menggunakan metode penelitian yuridis normatif dengan dua pendekatan yaitu: pendekatan undang-undang (statue approach), pendekatan konseptual (conceptual approach). Penelitian ini juga menggunakan pendekatan dari segi ekonomi (economic analysis of law).

Sumber bahan hukum dari penelitian ini terdiri dari: pertama, sumber bahan hukum primer, mencakup semua peraturan perundang-undangan yang berhubungan dengan permasalahan penelitian terutama Undang-undang No. 8 Tahun 1995 tentang Pasar Modal (UUPM), Undang Undang No. 40 Tahun 2007 tentang Perseroan Terbatas (UUPT 2007) serta peraturan perundang-undangan yang berkaitan dengan isu hukum dalam penelitian ini; dan kedua, sumber bahan hukum sekunder, yaitu semua publikasi yang berhubungan dengan permasalahan meliputi buku-buku teks, kamus-kamus hukum dan jurnal-jurnal hukum. Analisis bahan hukum dilakukan dengan menggunakan penalaran yuridis dan ekonomi untuk memberikan argumentasi hukum dan ekonomi.

\section{Pembahasan}




\section{Konsep Hukum tetang Pengaturan}

Pengaturan merupakan cara atau perbuatan mengatur yang dituangkan dalam peraturan perundang-undangan sebagai suatu aturan hukum yang menjadikan orang dengan kepastian ditetapkan oleh pengemban kewenangan hukum. ${ }^{7}$ Pengaturan kegiatan pasar modal di Indonesia menurut UUPM 1995 dilakukan oleh Badan Pengawas Pasar Modal (Bapepam) yang telah bertransformasi menjadi Otoritas Jasa Keuangan sejak dikeluarkannya Undang-Undang No. 21 Tahun 2011 tentang Otoritas Jasa Keuangan (selanjutnya disebut UU OJK 2011). Pasca beralihnya Bapepam kepada OJK seluruh pengaturan dialihkan ke OJK tetapi dengan substansi aturan yang tetap sama karena perubahan hanya pada lembaga yang mengeluarkan aturan ${ }^{8}$. Pengaturan jika dikaitkan dengan istilah hukum berarti regulasi atau peraturan hukum (perundang-undangan). Peraturan perundang-undangan dapat diartikan sebagai sebuah produk hukum dan proses hukum ${ }^{9}$. Peraturan Perundang-undangan sebagai produk hukum merupakan penataan jenisjenis hukum yang masing-masing mempunyai kedudukan, serta hubungan hierarkis fungsional. Peraturan Perundang-undangan dalam arti proses adalah untuk menyebut rangkaian kegiatan dalam pembentukan hukum/peraturan hukum tertulis, mulai dari penyusunan naskah akademik, penyusunan rancangan suatu jenis, pembahasan/persetujuan, pengesahan, pengundangan sampai pembentukan peraturan-peraturan pelaksanaan, serta pembentukannya berdasarkan asas-asas -undangan.

Peraturan perundang-undangan haruslah memuat landasan filosofis sebagai cita-cita masyarakat, penuh dengan rasa adil dan tuntutan

7 Raffles, "Pengaturan dan Model Alternatif Penyelesaian Sengketa dalam Perundang-undangan Indonesia", Inovatif, Vol. 2 Vol. 3 2010, Jambi: Fakultas Hukum Universitas Jambi, hlm. 118.

8 Susi Muliyanti dkk., "Analisis Yuridis Kedudukan Badan Pengawas Pasar Modal (Bapepam) Setelah Berlakunya Undang-undang No. 21 Tahun 21 tentang Otoritas Jasa Keuangan", USU Law Journal, Vol. II No. 2 Edisi Nov 2011, Medan: Program Studi Magister dan Doktor Ilmu Hukum Fakultas Hukum Universitas Sumatra Utara, hlm. 88.

9 Retno Saraswati, "Sumber Hukum dan Tata Urutan Peraturan Perundang-undangan di Indonesia", Media Hukum, Vol. IX No. 2 Edisi April 2009, Yogyakarta: Universitas Muhammadiyah, hlm. 1-2. moralitas masyarakat. ${ }^{10}$ Artinya tolok ukur pencarian kebenaran dalam hukum didasarkan pada pengkajian berbagai masalah sehingga dapat menjadi pedoman dalam mengatur pola perilaku masyarakat serta menciptakan keadilan dan kepastian hukum bagi setiap warga Negara. ${ }^{11}$ Berdasarkan alasan ini, maka peraturan perundangundangan di Indonesia haruslah terus-menerus diperbaharui agar peran dan fungsinya sebagai pedoman tingkah laku (fungsi ketertiban) dalam hidup bersama yang imperatif dan efektif sebagai penjamin keadilan di dalam masyarakat tetap terjaga. ${ }^{12}$ Pengaturan pasar modal di Indonesia telah diatur dalam Undang-undang No. 8 Tahun 1995 tentang Pasar Modal (selanjutnya disebut UUPM 1995). Undang-undang ini dipakai sebagai landasan untuk menjamin kepastian hukum pihak-pihak yang melakukan kegiatan di pasar modal serta melindungi kepentingan masyarakat pemodal dari praktik yang merugikan. Sasaran yang ingin dicapai diantaranya adalah menciptakan kerangka hukum yang kuat di bidang pasar modal dan meningkatkan transparansi atau keterbukaan di pasar modal. ${ }^{13}$ Keterbukaan menjadi prinsip dan persoalan inti dalam pasar modal sekaligus jiwa pasar modal itu sendiri karena dipakai sebagai landasan pertimbangan baik para pelaku di pasar modal untuk melakukan aktivitas pasar modal secara rasional. ${ }^{14}$ Prinsip ini menuntut perusahaan yang akan go public maupun yang sudah go public membuka informasi yang mengandung faktor material tentang perusahaan secara transparan. ${ }^{15}$ Keterbukaan akan meningkatkan keperca-

10 M. Husni, "Moral dan Keadilan sebagai Landasan Penegakan Hukum yang Responsif", Jurnal Equality, Vol. 11 No. 1 Edisi Februari 2006, Medan: Fakultas Hukum Universitas Sumatra Utara, hlm. 3.

11 Gede Sudika Mangku Dewa, "Fungsi Evaluatif Filsafat Hukum terhadap Hukum Positif Indonesia", Pendecta, Vol. 8 No.1 Edisi Januari 2013, Semarang: Fakultas Hukum Universitas Negeri Semarang, hlm. 34.

12 ibid, hlm. 33.

13 Raffles, “Analisis Penerapan Prinsip Keterbukaan Di Pasar Modal Dalam Kaitannya Dengan Pengelolaan Perusahaan Yang Baik", Inovatif, Vol. 4 No. 5 2011, Jambi: Fakultas Hukum Universitas Jambi, hlm. 28.

14 Priyanta Putra dkk, "Insider Trading dalam Kegiatan Pasar Modal menurut Undang-Undang Nomor 8 Tahun 1995", Kertha Wicara, Vol.1 No.1 2012, Denpasar: Fakultas Hukum Universitas Udayana, hlm. 1.

15 Megarita, "Scripless Trading dan Prinsip Keterbukaan Menciptakan Pasar yang Efisien dan Mengurangi Resiko 
yaan masyarakat terhadap pasar modal. Berdasarkan uraian di atas, maka konsep hukum tentang pengaturan adalah sumber hukum formil berupa peraturan perundang-undangan yang merupakan suatu keputusan yang tertulis, dibentuk oleh lembaga negara atau pejabat yang berwenang, serta mempunyai kekuatan untuk mengikat umum.

\section{Konsep Hukum tentang Saham Tanpa Nilai No- minal}

Saham menurut UUPM 1995 Pasal 1 ayat 5 merupakan salah satu jenis efek. Saham merepresentasikah jumlah kontribusi modal oleh pemilik kepada perusahaan ${ }^{16}$. Saham sebagai bentuk penyertaan modal dalam pemilikan suatu Perseroan Terbatas diterbitkan dalam jumlah tertentu sesuai dengan kebutuhan modal PT. ${ }^{17}$ Modal Perseroan menurut UUPT 2007 terdiri dari modal dasar, modal ditempatkan dan modal disetor penuh. Modal dasar Perseroan adalah seluruh nilai nominal saham yang menggambarkan jumlah maksimal modal yang dapat ditempatkan dan disetor penuh. Berdasarkan pemahaman ini suatu Perseroan tidak dapat memiliki modal ditempatkan dan disetor yang jumlahnya melampaui jumlah modal dasar yang disebutkan dalam Anggaran Dasar (AD) Perseroan. Modal dasar Perseroan kesemuanya terbagi-bagi ke dalam saham.

Saham dengan nilai nominal secara esensial tidak berbeda dengan saham tanpa nominal. ${ }^{18}$ Keduanya dikeluarkannya untuk sebuah nilai. Saham dengan nilai nominal dikeluarkan untuk perolehan kas atau property sebesar nilai yang ditetapkan sementara nilai kas dan properti dari saham tanpa nilai nominal dilekatkan o-

Investasi”, Jurnal Equality, Vol. 10 No. 1 Edisi Februari 2005, Medan: Fakultas Hukum Universitas Sumatra Utara, hlm. 26.

16 Victor Morawetz, "Share Without Nominal or Par Value", Harvard Law Review, Vol. 26 No. 8 Edisi Juni 1913, Massachusetts: Harvard Law School, The University of Harvard, hlm. 729.

17 Liana Endah Susanti, "Perkembangan Pengaturan Perlindungan terhadap Pemegang Saham Perseroan Terbatas di Indonesia", Media Soerjo, Vol. 7 No. 2 Edisi Oktober 2010, Ngawi: Universitas Soerjo, hlm. 18.

18 Frederick H. Hurdman, "No Par Value Stock", Journal of Accountacy, Edisi Feb 1924, New York: American Institute of Certified Public Accountants (AICPA), hlm. 91 100 leh saham itu sendiri berdasarkan harga pasarnya.

Nilai nominal yang dinyatakan dalam saham berfungsi untuk membatasi kewajiban dan tanggungjawab pemegang saham terhadap hutang perusahaan dan melindungi kepentingan kreditur, ${ }^{19}$ yaitu: Fixed the maximum amount that a shareholder in a company limited by shares would have to pay by way of statutory liability; It will be a fraud against the present shareholders and creditors to issue sharres at discount unless under specially provided circumtances. Issuing shares at discount has the effect of assigning a lower than par value to the shares thus lowering the statutory liability of the new shareholders.

Pembatasan tanggung jawab pemegang saham sebagai karakteristik bisnis korporasi modern menyebabkan kreditor hanya dapat mengklaim aset perusahaan. Nilai nominal saham merupakan sebuah ukuran yang diberikan untuk menjamin kreditor bahwa perusahaan memiliki cukup aset untuk melunasi hutangnya. Fungsi perlindungan kepada kreditur ini dalam banyak kasus tidak tercapai karena jumlah nominal modal perusahaan jarang yang menunjukkan jumlah modal aktualnya atau jumlah yang benar-benar dikontribusikan oleh pemegang saham. Situasi ini mendorong terbitnya peraturan mengenai saham tanpa nilai nominal. ${ }^{20}$

Nominal saham menurut Pasal 54 UUPM dapat dipecah-pecahkan dan ada perbedaan antara saham nominal dengan pecahan nilai nomial saham. Perbedaan tersebut adalah sebagai berikut. Pertama, anggaran dasar dapat menentukan pecahan nilai nominal saham; kedua, Pemegang pecahan nilai nominal saham tidak diberikan hak suara perseorangan, kecuali pemegang pecahan nilai nominal saham, baik sendiri atau bersama pemegang pecahan nilai nominal saham lainnya yang klasifikasi sahamnya sama memiliki nilai nominal sebesar 1 (satu) nominal saham dari klasifikasi tersebut; ketiga, Ketentuan sebagaimana dimaksud dalam Pasal 52 ayat

\footnotetext{
19 James C. Bonbright, "The Danger of Shares Without Par Value", Colombia Law Review, Vol. XXIX No. 5 Edisi Mei 1924, New York: Columbia Law Students, hlm. 451.
}

20 Victor Morawetz, op.cit, hlm. 73. 
(4) dan ayat (5) mutatis mutandis berlaku bagi pemegang pecahan nilai nominal saham.

Saham tanpa nominal, artinya saham yang diterbitkan tidak dikaitkan dengan penyebutan sejumlah nilai tertentu dalam setiap lembar saham, "a no par value regime would mean that a share is not given any arbitrary par value and the directors or promoters can issue the shares at its market price or at a price that they deem fit or reasonable". ${ }^{21}$ Nilai nominal dalam setiap lembar saham yang diterbitkan oleh perseroan tidak tercantum dalam saham. Artinya tidak diperlukan lagi penyebutan modal dasar atau authorized capital, yang dapat dibedakan dengan issued capital dan paid up capital. Setiap lembar saham yang dikeluarkan perseroan tidak lagi dibatasi oleh berapa besar modalnya. Besarnya modal dasar suatu Perseroan tidak lagi dikaitkan dengan nilai nominal saham.

Terdapat 2 bentuk pengaturan saham tanpa nilai nominal di beberapa negara, yaitu yaitu bentuk mandatory (keharusan) dan optional (pilihan). ${ }^{22}$ Salah satu negara yang mengadopsi bentuk mandatory adalah Singapura. Saham tanpa nilai nominal di Singapura diatur dalam Pasal 62 ayat (2) Singapore Companies Act Cap 50 , "shares of a company have no par or nominal value, (2) SubSection (1) shall apply to all shares, whether issued before, on or after 30th January 2006". New York dan Massachusetts menerapkan saham tanpa nilai nominal secara optional, "par value stock can not leggaly issued in New York and Massachustts for lessthan par, so the par value stock is considerent first and the capital value of no par stock is usually the excess of the consideration received over the amount of par value stock issued. ${ }^{23}$

Indonesia berdasarkan UUPT 2007 lebih ke sistem optional. Emiten dapat menerbitkan sahamnya tanpa nilai nominal atau dengan nilai

21 Yew Kee Ho dan Lan Luh Tuh, "The Par Value of Shares : An Irrelevant Concept in Modern Company Law", Singapore Journal of Legal Studies, Edisi 1999, Singapura: National University of Singapore, Faculty of Law, hlm. 10.

22 Gunawan Widjaya, op.cit. hlm. 28.

23 Percival F. Brundage, "Treatment of No par value Stock in New York, New Jersey, and Massachusetts", The Journal of Accountacy, Vol. 41 No. 4 Edisi April 1926, New York: American Institute of Certified Public Accountants (AICPA), hlm. 245. nominal. Kecuali UUPM baru mengatur lain. Perubahan saham dengan nilai nominal ke rezim saham tanpa nilai nominal harus diatur lebih lanjut agar penerapan saham tanpa nilai sesuai dengan diatur dalam Pasal 31 ayat (2) dapat diterapkan di $\mathrm{BEI}$, sebelum bearish terulang lagi. Berdasarkan pandangan-pandangan yang telah diuraikan, maka saham tanpa nilai nominal menurut kesimpulan penulis ialah saham yang tidak mempunyai nilai nominal sehingga nilainya tidak tercantum dalam sertifikat saham, namun tetap mempunyai nilai buku (book value) yang menggambarkan harga saham berdasarkan harga pasar (market value) yang tercantum dalam pembukuan perseroan.

\section{Konsep Hukum tentang Pasar Modal Indonesia}

Pasar modal sebagai institusi ekonomi mempunyai peran penting dalam perkembangan dunia usaha ${ }^{24}$ karena berfungsi sebagai tempat kegiatan perusahaan dalam rangka mencari dana untuk pembiayaan usahanya. ${ }^{25}$ Pasar modal mempertemukan penjual dan pembeli dana-dana jangka panjang yang salah satunya disebut efek atau saham ${ }^{26}$. Kegiatan pasar modal di Indonesia diatur dalam UUPM 1995 Pasal 1 ayat (13) yang mencakup semua kegiatan yang bersangkutan dengan penawaran umum serta perdagangan efek, penerbitan efek oleh perseroan publik serta lembaga dan profesi yang berkaitan dengan efek.

Penawaran Umum adalah kegiatan penawaran Efek yang dilakukan oleh Emiten untuk menjual Efek kepada masyarakat berdasarkan tata cara yang diatur dalam Undang-undang dan peraturan pelaksanaannya (UUPM 1995 Pasal 1 ayat (15)). Kegiatan Penawaran Umum (Initial Public Offering) dilakukan di pasar perdana dan setelah selesai efek diperdagangkan di pasar se-

24 Tandi Pada Palayukan dkk, "Analisis terhadap Larangan Praktik Insider Trading di Pasar Modal", USU Law Journal, Vol. II No. 2 Edisi Nov 2013, Medan: Program Studi Magister dan Doktor Ilmu Hukum Fakultas Hukum Universitas Sumatra Utara, hlm. 92.

25 Raffles, op.cit, hlm. 26

26 Made Dwi Juliana dkk., "Perlindungan Hukum terhadap Investor Bila terjadi Insider Trading", Kertha Wicara, Vol. 2 No. 1 Edisi Februari 2013, Denpasar: Fakultas Hukum Universitas Udayana, hlm. 1. 
kunder atau bursa efek ${ }^{27}$. Perdagangan di pasar perdana terjadi antara perusahaan (emiten) dengan underwriter (penjamin emisi). Harga saham di pasar perdana ditentukan berdasarkan kesepakatan antara emiten dan penjamin emisi, sedangkan harga saham di pasar sekunder ditentukan berdasarkan kekuatan permintaan dan penawaran pasar ${ }^{28}$.

Perdagangan efek di pasar modal melibatkan lembaga dan profesi penunjang pasar modal. Profesi penunjang pasar modal adalah segolongan pihak lain yang oleh hukum dikelompokan sebagai pihak yang mempunyai fungsi untuk ikut menunjang pasar modal. ${ }^{29}$ Lembaga profesi pasar modal sesuai dengan UUPM 1995 terdiri dari kustodian, biro administrasi efek dan wali amanat (diatur dalam Bab VI) sementara profesi penunjang pasar modal mencakup akuntan, konsultan hukum, penilai, notaris dan profesi lain yang ditetapkan oleh peraturan pemerintah (diatur dalam BAb VII).

Kegiatan pasar modal di Indonesia selain diatur dalam UUPM 1995 juga diatur dalam Peraturan Menteri Keuangan (Permenkeu) dan Keputusan Menteri Keuangan (Kepmenkeu), peraturan OJK dan regulasi lain yang terkait pasar modal. Regulasi ini diantaranya adalah Undang undang (UU) No. 24 Tahun 2002 tentang Surat Utang Negara (Lembaran Negara Tahun 2002 Nomor 110), 2) UU No. 8 Tahun 2010 tentang Tindak Pidana Pencucian Uang (Lembaran Negara Tahun 2010 Nomor 122), UU No.30 tentang Arbitrase dan Alternatif Penyelesaian Sengketa Modal (Lembaran Negara Tahun 1999 Nomor 138) dan UU No. 8 Tahun 1997 tentang Dokumen Perusahaan (Lembaran Negara Tahun 1997 Nomor

27 Ary Sukma Lutfianto, "Determinan Initial Return Saham Go Public Tahun 2006-2011", Jurnal Ilmu Manajemen, Vol. 1 No. 1 Edisi Januari 2013, Surabaya: Universitas Negeri Surabaya, hlm. 364.

28 Elyzabet Indrawati Marpaung dan Bram Hadianto, "Pengaruh Profitabilitas dan Kesempatan Investasi terhadap Kebijakan Dividen: Studi Empirik pada Emiten Pembentuk Indeks LQ45 di Bursa Efek Indonesia", Jurnal Akuntansi, Vol. 1 No. 1 Edisi Mei 2009, Bandung: Fakultas Ekonomi Jurusan Akuntansi Universitas Maranatha, hlm. 70.

29 I Kadek Andi Wijaya dan Ni Nyoman Sukeni, "Tanggug Jawab Emiten dan Profesi Penunjang Pasar Modal atas Adanya Prospektus yang Tidak Benar dalam Kegiatan di Pasar Modal”, Kertha Semaya, Vol. 01 No. 01 Edisi September 2013, Denpasar: Program Studi Ilmu Hukum Fakultas Hukum Universitas Udayana, hlm. 2.
18). Konsep hukum pasar modal Indonesia oleh karenanya yaitu kegiatan yang terjadi di Indonesia dan sesuai dengan UUPM 1995 yaitu bersangkutan dengan penawaran umum dan perdagangan Efek, perusahaan publik yang berkaitan dengan efek yang diterbitkannya, serta lembaga dan profesi yang berkaitan dengan Efek.

\section{Manfaat Pengaturan Saham Tanpa Nilai No- minal dalam Hukum Pasar Modal Indonesia}

Manfaat pengaturan saham tanpa nilai nominal dapat diketahui dari makna filosofisnya. Berdasarkan makna ontologis, saham tanpa nilai nominal merupakan salah satu alternatif penyelesaian krisis di pasar modal. Berdasarkan aspek aksiologis pengaturan saham tanpa nilai nominal memberikan beberapa nilai manfaat.

\section{Pengaturan Saham Tanpa Nilai Nominal Berda- sarkan Makna Ontologis}

Pencarian alternatif cara untuk mengatasi bearish di pasar modal Indonesia dengan perdagangan saham tanpa nilai nominal merupakan kebutuhan pelaku pasar modal. Perdagangan saham tanpa nilai nominal walaupun telah dikenalkan dalam Pasal 33 ayat (2) UUPT 2007 masih berjalan lambat karena belum tersedianya aturan lebih lanjut yang dapat digunakan dalam penerapan perdagangan saham tanpa nilai nominal. Kelambatan ini menjadi salah satu penyebab bearish di pasar modal tidak segera teratasi.

Pada saat kondisi pasar buruk di mana harga saham di pasar dibawah harga nominal (nominee value) menyebabkan Emiten kesulitan untuk melakukan right issue, atau melakukan penawaran umum padahal Emiten membutuhkan dana segar (fresh money) dari pasar modal . Dana segar dari pasar modal dibutuhkan karena dalam keadaan krisis ekonomi mencari dana melalui dunia perbankan akan mengalami kesulitan. Perbankan akan menetapkan bunga tinggi sehingga dana dari pasar modal akan mengurangi kompetisi perseroan dalam memperoleh pembiayaan perbankan.

Perolehan dana melalui pasar modal mengalami beberapa kendala atau permasalahan akibat belum adanya aturan yang dapat diterap- 
kan dalam perdagangan saham tanpa nilai nominal karena beberapa alasan. Pertama, investor tidak mau membeli saham baru dengan harga sesuai nominal karena harga saham di pasar (market value) di bawah harga nominal; kedua, kondisi akan menjadi tidak adil bagi pemegang saham lama, jika haknya sama dengan pemegang saham baru yang membeli saham dengan nominal lebih rendah dari market value karena terjadinya bearish. Tindakan investor ini menerapkan prinsip ekonomi, yaitu membeli dengan harga rendah (murah) dan menjual di harga tinggi (mahal), sehingga investor mendapat keuntungan (capital gain) seoptimal mungkin. Permasalahan ini akan penulis jelaskan melalui ilustrasi sebagai berikut. Pertama, pada saat IPO tanggal 2 Januari 1997, emiten yaitu Alumindo Light Metal Industry Tbk (ALMI) menawarkan sahamnya dengan nilai nominal Rp. 500 perlembar. Harga Saham pada 2007 adalah Rp.950. Pada tahun 2009, harga saham di bawah harga nominal, yaitu Rp.495 (Pebruari 2009), Rp.475 (Maret 2009) dan Rp.415 (April 2009). Pada Pebruari, Maret, April 2009 market value saham ALMI di bawah harga nominal. Kedua, pada saat IPO pada tanggal 21 Januari 1999, emiten yaitu Sumi Indo Kabel Tbk (IKBI) harga nominal saham Rp.1.000 perlembar. Namun market valuenya di bawah harga nominal pada bulan Januari 2008 sebesar Rp.850, Februari 2008 sebesar Rp.650, Januari 2009 sebesar Rp.390, Februari 2009 sebesar Rp. 380.39.

Emiten (ALMI dan IKBI) akan sulit untuk melakukan penambahan modal melalui pasar modal (right issue) karena market value ke dua saham tersebut dibawah harga nominalnya. Penambahan modal di bawah nilai nominal akan menyebabkan pemegang saham lama (ALMI dan IKBI) akan merasa dirugikan karena investor baru membeli harga dibawah harga nominal, dengan hak yang sama dengan pemegang saham lama, karena nominal saham tidak menggambarkan hak pemegang saham. Hak pemegang saham ditentukan oleh jumlah lembar saham yang dimiliki. Satu lembar saham mempunyai hak satu suara dalam voting.

Penjualan saham dibawah harga nominal hanya boleh terjadi jika emiten melakukan pe- ngurangan modal yang ditempatkan sebagaimana yang diatur Pasal 47 ayat (1) UUPT 2007, yaitu Keputusan RUPS tentang pengurangan modal ditempatkan dan disetor. Caranya dilakukan penarikan kembali saham atau penurunan nilai nominal saham. Penurunan nilai nominal ini dapat dilakukan dengan pemecahan saham.

Aturan dalam UUPT 2007 ini menunjukkan bahwa dengan alasan pengurangan modal saja saham bisa dijual dibawah harga nominal tetapi dengan alasan lain seperti karena bearish, menurut Pasal 47 ayat (1) tidak diperbolehkan melakukan penarikan kembali saham. Penarikan kembali saham sebagaimana dimaksud pada ayat (1) hanya dapat dilakukan terhadap saham yang telah dibeli kembali oleh Perseroan atau terhadap saham dengan klasifikasi yang dapat ditarik kembali. Kedua permasalahan ini tidak akan terjadi kalau saham yang dijual di bursa efek, adalah saham tanpa nilai nominal.

\section{Pengaturan Saham Tanpa Nilai Nominal Berda- sarkan Makna Aksiologis}

Berdasarkan aspek aksiologis pengaturan saham tanpa nilai nominal memberikan beberapa nilai manfaat. Manfaat berlakunya saham tanpa nilai nominal seperti dijelaskan sebelumnya telah teruji di beberapa negara yang telah memberlakukan saham tanpa nilai nominal pada saat bearish. Negara yang yang telah menerapkan saham tanpa nilai nominal lebih cepat pulih perdagangannya di pasar modal.

Saham tanpa nilai bermanfaat dalam mempermudah perusahaan untuk melakukan penambahan modalnya sesuai yang dibutuhkan pada nilai pasarnya ${ }^{30}$. Keadaan akan berbeda jika peraturan pasar modal suatu negara menganut rezim nilai nominal. Perusahaan yang harga pasar sahamnya lebih kecil dari nilai nominalnya kesulitan menambah modal dengan menjual saham. Mereka dipaksa untuk meminjam uang dari bank. Peningkatan rasio hutang perusahaan akan memperberat beban keuangan karena meningkatnya beban bunga meningkat terutama bagi perusahaan-perusahaan yang sedang mengalami kesulitan keuangan. Penambahan modal

\footnotetext{
30 Morawetz Victor, op.cit, hlm. 730-731.
} 
di bawah nilai nominal boleh dilakukan dengan syarat perusahaan mengurangi nilai nominal saham yang beredar. Prosedur ini memerlukan biaya administrasi yang cukup tinggi. ${ }^{31}$ Penerapan saham tanpa nilai nominal mengijinkan penerbitan saham pada harga berapapun sesuai dengan harga pasar tanpa terkendala dengan besarnya nilai nominal.

Berdasarkan penelitian di Amerika Serikat membuktikan kecenderungan perpindahan dari saham dengan nilai nominal ke saham tanpa nilai telah mencapai beberapa hasil atau keuntungan, diantaranya modal bekerja tanpa kuatir adanya inflasi dari nilai asset dalam pembukuan, saham dapat diterbitkan dengan nilai senyatanya tanpa pertimbangan nilai nominal dan pemegang saham dijamin bahwa saham yang diterbitkan akan dibayar penuh. ${ }^{32}$ Hasil penelitian yang dilakukan oleh British Institute' Council, ${ }^{33}$ menunjukkan ada 4 (empat) manfaat saham tanpa nilai nominal. Pertama, The elimination of the "par value label" permits the investor to be free from at least one misconceptions as to the real worth of his shares; kedua, such shares facilitate the marketability of a company's share because the simple processof a share split becomes the equivalentof shares bonus; ketiga, such shares enable a company to make a fresh issue of share at a price in relation to market value of the existing shares; keempat, dividens can be declared as an actual cash amount per share instead of as a percentage of the share"s nominal value.

Penghapusan nilai nominal akan menghindarkan miskonsepsi terhadap kekayaan riil dari sebuah sertifikat saham. Nilai nominal yang tertera di sertifikat saham tidak menunjukkan nilai riil dari aset atau kekayaan yang menjadi hak

31 Paolo Santella dan Riccardo Turrini, "Capital Maintenance in EU: Is the Second Company Law Directive Really That Restictive?", European Business Organization Law Review, Vol. 9 2008, Cambridge: The Cambridge University Press, hlm. 444.

32 Frederick H. Hurdman, "Capital Stock Of No Par Value", Journal Of Accountacy. Edisi Oktober 1919, New York: American Institute of Certified Public Accountants (AICPA), hlm. 251.

33 Anonymous, "British Institute' Council list four advantages of no par value shares", Journal Of Accountacy, Edisi Oktober 1953, New York: American Institute of Certified Public Accountants (AICPA), hlm. 443. pemegang saham. Hak pemegang saham didasarkan pada jumlah lembar saham yang dimiliki yang nilainya tergantung pada kondisi keuangan perusahaan.

Penerapan saham tanpa nilai nominal juga dapat mencegah kecurangan ${ }^{34}$. Stock watering (saham diterbitkan dengan nilai yang lebih besar dari aset yang sebenarnya dimiliki oleh perusahaan) adalah salah satu kecuarangan yang terjadi. Stock watering mengecoh pihakpihak yang berkepentingan atas modal yang diinvestasikan di dalam perusahaan. Solusi atas masalah ini adalah sederhana yaitu mengijinkan saham dikeluarkan tanpa nilai nominal sehingga investor tidak tertipu dengan penampilan palsu dan akan menilai saham berdasarkan nilai riil dari aset perusahaan.

Penerbitan saham tanpa nominal secara pembukuan perusahaan dapat dilakukan dan bahkan pembukuannya lebih sederhana. Kesederhanaan pembukuan terjadi dalam kasus ketika perusahaan menerima kas yang nilainya lebih besar dari nilai nominal saham yang diterbitkan. ${ }^{35}$ Kelebihan pembayaran ini dikenal dengan surplus atau agio saham. Ilustrasi dari pembukuan ini misalkan PT. ABC mengotorisasi dan menerbitkan saham sebanyak 1.000 lembar saham dengan nilai nominal Rp.25.000. Saham tersebut terjual dengan harga Rp.26.000. Pembukuan yang dilakukan perusahaan adalah:

$\begin{array}{lr}\text { Kas } & 26.000 .000 \\ \text { Modal Saham } & 25.000 .000 \\ \text { Agio Saham } & 1.000 .000\end{array}$

Berbeda dengan saham dengan nilai nominal, apabila perusahaan mengotorisasi dan menerbitkan saham tanpa nilai nominal sebanyak 1.000 lembar serta terjual dengan harga Rp.26.000 maka pembukuannya adalah:

$\begin{array}{ll}\text { Kas } & 26.000 .000 \\ \text { Modal Saham } & 26.000 .000 .\end{array}$

Kesederhanaan pembukuan tidak hanya terjadi pada saat penerbitannya tetapi juga akan tampak di neraca perusahaan khususnya dalam struktur permodalannya. Neraca perusahaan

34 James C. Bonbright, op.cit, hlm. 454.

35 Frederick H. Hurdman, "No Par Value Stock", Journal Of Accountacy. Edisi Februari 1924, New York: American Institute of Certified Public Accountants (AICPA), hlm. 91-92. 
yang menerbitkan saham dengan nilai nominal akan tampak sebagai berikut:

$\begin{array}{lr}\text { Modal Saham } & 25.000 .000 \\ \text { Agio Saham } & 1.000 .000 \\ \text { Total Modal Saham } & 26.000 .000\end{array}$

Neraca perusahaan yang menerbitkan saham tanpa nilai nominal lebih sederhana:

Modal Saham 26.000.000

Penerapan saham tanpa nilai nominal belum dapat dilaksanakan karena belum ada aturan hukum sebagai aturan pelaksana Pasal 31 ayat (2) UUPT 2007. Harmonisasi antara hukum dan ekonomi tidak tercapai. Ketidakhamonisasi ini akan menghambat perkembangan perekonomian suatu negara dan tidak adanya kepastian hukum. Tindakan perusahaan yang tidak dapat dilakukan oleh pelaku pasar modal dan regulator pasar modal karena belum adanya pengaturan yang lebih lanjut untuk saham tanpa nilai nominal menurut teori economic analysis of law $^{36}$ adalah tindakan yang tidak efisien. Artinya perusahaan lebih banyak melakukan pengorbanan daripada menerima manfaatnya. Perusahaan seharusnya dapat memanfaatkan sumber daya sehingga dapat mencapai nilai yang tinggi.

Aturan dalam Pasal 31 ayat (2) UUPT 2007 merupakan terobosan yang bagus agar perusahaan dapat melakukan tindakan yang efisien. Perseroan di Indonesia mengenal dua rezim saham yaitu saham dengan dan tanpa nilai nominal. Saham tanpa nilai nominal tertutup atau terlarang bagi Perseroan yang tidak menerbitkan sahamnya di pasar modal. Perseroan Terbuka atau publik mempunyai pilihan dalam menerbitkan saham dengan atau nilai nominal untuk diperdagangkan di bursa efek.

Ketentuan Pasal 31 ayat (2) UUPT 2007 tidak dapat diterapkan di Bursa Efek Indonesia sepanjang belum ada undang-undang baru atau perubahan (amendemen) UUPM 1995. UUPM merupakan lex specialist dari UUPT 2007. Berdasarkan penelitian yang dilakukan oleh Hans B Christensen, ${ }^{37}$ perubahan peraturan pasar modal

36 Robert A. Posner, 1992, Economic Analysis Of Law, USA: Little, Brown and Company Law Book Division, page 10.

37 Hans B. Christensen, et al., "Capital-Market Effects of Securities Regulation: Hysteresis, Implementation, and akan berdampak positif pada kinerja bursa efek, secara signifikan menguntungkan perekonomian suatu negara. Perubahan itu berupa peraturan yang transparan, dan mempersulit perdagangan orang dalam (insider trading) akan meningkatkan likuiditas di bursa efek. Peraturan pasar modal Indonesia diharapkan berdampak positif bagi Bursa Efek Indonesia, yang pada gilirannya meningkatkan perekonomian Negara dan diharapkan dapat dinikmati oleh rakyat Indonesia.

\section{Penutup \\ Simpulan}

Berdasarkan analisis yang telah diuraikan di atas, beberapa simpulan yang bisa ditarik adalah sebagai berikut. Pertama, konsep hukum pengaturan adalah adalah sumber hukum formil berupa peraturan perundang-undangan yang terdiri beberapa unsur antara lain merupakan suatu keputusan yang tertulis, dibentuk oleh lembaga negara atau pejabat yang berwenang, dan mempunyai kekuatan untuk mengikat umum; kedua, konsep hukum saham tanpa nilai nominal adalah saham yang tidak mempunyai nilai nominal sehingga tidak tercantum dalam sertifikat saham, namun tetap mempunyai nilai buku (book value) yang menggambarkan harga saham berdasarkan harga pasar (market value) yang tercantum dalam pembukuan Perseroan; ketiga, konsep hukum pasar modal Indonesia adalah k kegiatan yang terjadi di Indonesia dan sesuai dengan UUPM 1995 yaitu bersangkutan dengan penawaran umum dan dan perdagangan efek, perusahaan publik yang berkaitan dengan efek yang diterbitkannya, serta lembaga dan profesi yang berkaitan dengan efek; keempat, manfaat pengaturan saham tanpa nilai nominal dapat dilihat dari makna filosofisnya. Berdasarkan makna ontologis, saham tanpa nilai nominal merupakan salah satu alternatif penyelesaian krisis di pasar modal. Berdasarkan aspek aksiologis pengaturan saham tanpa nilai nominal mempercepat pemulihan perdagangannya di pasar modal pada saat bearish. Penerapan saham tanpa nilai nominal juga dapat mencegah kecu-

Enforcement. Working Paper: 12-04, Edisi November 2011, The University of Chicago Both School Of Business, hlm. 36. 
rangan yaitu stock watering. Penerbitan saham tanpa nominal secara pembukuan perusahaan dapat dilakukan dan bahkan pembukuannya lebih sederhana. Manfaat penerapan saham tanpa nilai nominal terutama akan dirasakan oleh pelaku pasar modal itu sendiri, yang pada akhirnya dirasakan oleh masyarakat pada umumnya.

\section{Saran}

Berdasarkan hasil penelitian ini disarankan agar pemerintah Indonesia segera membuat peraturan baru agar saham tanpa nilai nominal yang sudah tercantum dalam Pasal 31 ayat (2) UUPT 2007 dapat diterapkan dalam perdagangan di bursa efek. Perubahan peraturan dapat dilakukan dengan membuat undang-undang pasar modal yang baru atau melakukan amandemen terhadap UUPM 1995. UUPM 1995 merupakan lex specialist dari UUPT 2007.

\section{Daftar Pustaka}

Anonymous. "British Institute' Council list four advantages of no par value shares". Journal Of Accountacy. Edisi Oktober 1953. New York: American Institute of Certified Public Accountants (AICPA);

Anonymous. "Corporations : No Par Value Stock". Michigan Law Review. Vol. 22 No. 8 Edisi Juni 1924. Michigan: The University of Michigan Law School;

Bonbright, James C. "The Danger of Shares Without Par Value". Colombia Law Review. Vol. XXIX No. 5 Edisi Mei 1924. New York: Columbia Law Students;

Brundage, Percival F. "Treatment of No par value Stock in New York. New Jersey. and Massachusetts". The Journal of Accountacy. Vol. 41 No. 4 Edisi April 1926. New York: American Institute of Certified Public Accountants (AICPA);

Christensen, Hans B. et al. "Capital-Market Effects of Securities Regulation: Hysteresis. Implementation. and Enforcement. Working Paper: 12-04. Edisi November 2011. The University of Chicago Both School Of Business;

Hendrawaty, Ernie. "Evaluasi Kinerja Reksa Dana Campuran Indonesia pada Kondisi Pasar Bearish". Jurnal Bisnis dan Manajemen. Vol. 6 No.3. Mei 2010. Lampung: Fakultas Ekonomi Universitas Lampung;
Ho, Yew Kee and Lan Luh Tuh. "The Par Value of Shares : An Irrelevant Concept in Modern Company Law". Singapore Journal of Legal Studies. Edisi 1999. Singapura: National University of Singapore. Faculty of Law;

Hurdman, Frederick H. "Capital Stock Of No Par Value". Journal Of Accountacy. Edisi Oktober 1919. New York: American Institute of Certified Public Accountants (AICPA);

....... "No Par Value Stock". Journal of Accountacy. Edisi Feb 1924. New York: American Institute of Certified Public Accountants (AICPA);

Husni, M. "Moral dan Keadilan sebagai Landasan Penegakan Hukum yang Responsif". Jurnal Equality. Vol. 11 No. 1 Edisi Februari 2006. Medan: Fakultas Hukum Universitas Sumatra Utara;

Japan Securities Research Institute. Securities Market In Japan. 2006. Tokyo: Japan Securities Research Institute;

Juliana, Made Dwi dkk. "Perlindungan Hukum terhadap Investor Bila terjadi Insider Trading". Kertha Wicara. Vol. 2 No. 1 Edisi Februari 2013. Denpasar: Fakultas Hukum Universitas Udayana;

Marpaung, Elyzabet Indrawati dan Bram Hadianto. "Pengaruh Profitabilitas dan Kesempatan Investasi terhadap Kebijakan Dividen: Studi Empirik pada Emiten Pembentuk Indeks LQ45 di Bursa Efek Indonesia". Jurnal Akuntansi. Vol. 1 No. 1 Edisi Mei 2009. Bandung: Fakultas Ekonomi Jurusan Akuntansi Universitas Maranatha;

Megarita. "Scripless Trading dan Prinsip Keterbukaan Menciptakan Pasar yang Efisien dan Mengurangi Resiko Investasi”. jurnal equality. Vol. 10 No. 1 Edisi Februari 2005. Medan: Fakultas Hukum Universitas Sumatra Utara;

Morawetz, Victor. "Share Without Nominal or Par Value". Harvard Law Review. Vol. 26 No. 8 Edisi Juni 1913. Massachusetts: Harvard Law School. The University of Harvard;

Muliyanti, Susi dkk. "Analisis Yuridis Kedudukan Badan Pengawas Pasar Modal (Bapepam) Setelah Berlakunya Undang-Undang No. 21 Tahun 21 tentang Otoritas Jasa Keuangan". USU Law Journal. Vol. II No. 2 Edisi Nov 2011. Medan: Program Studi Magister dan Doktor Ilmu Hukum Fakultas Hukum Universitas Sumatra Utara; 
Palayukan, Tandi Pada dkk. “Analisis terhadap Larangan Praktik Insider Trading di Pasar Modal". USU Law Journal. Vol. II No. 2. Edisi Nov 2013. Medan: Program Studi Magister dan Doktor Ilmu Hukum Fakultas Hukum Universitas Sumatra Utara;

Posner, Robert A. 1992. Economic Analysis of Law. USA: Little. Brown and Company Law Book Division;

Priyanta, Putra. dkk. "Insider Trading dalam Kegiatan Pasar Modal menurut Undang-undang Nomor 8 Tahun 1995". Kertha Wicara. Vol.1 No.1 2012. Denpasar: Fakultas Hukum Universitas Udayana;

$\mathrm{Pu}$, Shen. "The P/E Ratio and Stock Market Performance". Economic Review. Vol. 85. No. 4 Fourth Quarter 2000. Kansas: Federal Reserve Bank of Kansas City;

Raffles. "Pengaturan dan Model Alternatif Penyelesaian Sengketa dalam Perundang-undangan Indonesia". Inovatif. Vol. 2 Vol. 3 2010. Jambi: Fakultas Hukum Universitas Jambi;

-.--.-. "Analisis Penerapan Prinsip Keterbukaan di Pasar Modal Dalam Kaitannya Dengan Pengelolaan Perusahaan Yang Baik". Inovatif. Vol. 4 No. 5 Tahun 2011. Jambi: Fakultas Hukum Universitas Jambi;

Santella, Paolo and Riccardo Turrini. "Capital Maintenance in EU: Is the Second Company Law Directive Really That Restictive?". European Business Organization Law Review. Vol. 9 2008. Cambridge: The Cambridge University Press;

Saraswati, Retno. "Sumber Hukum dan Tata Urutan Peraturan Perundang-undangan di Indonesia". Media Hukum. Vol. IX No. 2. Edisi April 2009. Yogyakarta: Universitas Muhammadiyah;

Simbolon, Robinson. "Pentingnya Perubahan Undang-undang Nomor 8 Tahun 1995 Tentang Pasar Modal". Jurnal Hukum Bisnis. Vol. 14. Edisi Juli 2003. Jakarta: Yayasan Pengembang Hukum Bisnis;

Sudika, Dewa Gede Mangku. "Fungsi Evaluatif Filsafat Hukum terhadap Hukum Positif Indonesia". Pendecta. Vol. 8 No.1 Edisi Januari 2013. Semarang: Fakultas Hukum Universitas Negeri Semarang;

Sukma, Lutfianto Ary. "Determinan Initial Return Saham Go Public Tahun 2006-2011". Jurnal Ilmu Manajemen. Vol. 1 No. 1 Edisi Januari 2013. Surabaya: Universitas Negeri Surabaya;
Susanti, Liana Endah. "Perkembangan Pengaturan Perlindungan terhadap Pemegang Saham Perseroan Terbatas di Indonesia". Media Soerjo. Vol. 7 No. 2 Edisi Oktober 2010. Ngawi: Universitas Soerjo;

Widjaya, Gunawan. “ Aspek Hukum Saham Tanpa Nilai Nominal dan Implikasinya Bagi PT Terbatas dan Pasar modal Indonesia". Jurnal Hukum Bisnis. Vol. 28 No. 32009. Jakarta: Yayasan Pengembang Hukum Bisnis.

Wijaya, I Kadek Andi dan Ni Nyoman Sukeni. "Tanggung Jawab Emiten dan Profesi Penunjang Pasar Modal atas Adanya Prospektus yang Tidak Benar dalam Kegiatan di Pasar Modal". Kertha Semaya. Vol. 01 No. 01 Edisi September 2013. Denpasar: Program Studi Ilmu Hukum Fakultas Hukum Universitas Udayana; 